\title{
Quick Identification of the Time of Maturation of Artisanal Minas Cheese by FTIR-ATR Spectroscopy and Multivariate Techniques
}

\author{
Josane C. de Jesus, ${ }^{a}$ Grazielly J. Silva, ${ }^{a}$ Ben-Hur R. F. Gonçalves, ${ }^{a}$ Marcelo R. de Souza, ${ }^{b}$ \\ Leandro S. Santos ${ }^{a}$ and Sibelli P. B. Ferrão ${ }^{\circledR} * a$ \\ aPrograma em Engenharia e Ciência de Alimentos, Universidade Estadual do Sudoeste da Bahia (UESB), \\ Rodovia BR 415, km 03, s/n, 45700-000 Itapetinga-BA, Brazil \\ ${ }^{b}$ Escola de Veterinária, Universidade Federal de Minas Gerais, 31270-901 Belo Horizonte-MG, Brazil
}

\begin{abstract}
The objective of this work is the identification of cheese maturation time using attenuated total reflection Fourier transform spectroscopy (FTIR-ATR) data and analytical measurements associated with chemometrics techniques. Minas artisanal cheeses were collected from 8 producers matured at times 1, 7, 14, 21, 28, 45 and 60 days, fractioned in rind and crumb for moisture, water activity $\left(\mathrm{a}_{\mathrm{w}}\right)$, dry in fat extract, $\mathrm{pH}$, acidity, ashes, protein, extent and depth of proteolysis, color and identification of functional groups in FTIR-ATR. Principal component analysis (PCA), multiple linear regression (MLR) and partial least squares (PLS) techniques were performed on the dataset. PCA was used to assess differences and similarities of the samples. The best results to predict the maturation time were using MLR for analytical measurements in the portion of the crumb, with coefficient of determination $\left(R^{2}\right)=0.92$, root mean square error of validation $($ RMSEV $)=5.4$ days and PLS for FTIR-ATR with $\mathrm{R}^{2}=0.92$, RMSEV $=5.3$ days. The results indicated that the FTIR-ATR was adequate to predict maturation times. Although, it does not eliminate the need for more detailed chemical analysis.
\end{abstract}

Keywords: dairy products, chemometrics, maturation

\section{Introduction}

Minas artisanal cheese is a typical Brazilian product. Its varieties are named according to their geographical origin (Serro, Canastra, Serra do Salitre, Araxá, Campo das Vertentes, Cerrado and Triângulo Mineiro). It is a product obtained from raw milk and "dripping", which is the whey of the fermented cheese originated from the production of the previous day, to be used in the fermentation of the production of the day. ${ }^{1,2}$

As it is a handcrafted product, it has in its elaboration a great load of historical and cultural tradition, having importance in the economic aspect, since many family producers have in the artisanal cheese of Brazil their main source of income. This type of cheese has stood out nationally and internationally due to its high quality and distinctive flavors, becoming a major dairy product, produced in many countries in Europe and the Americas, and by winning important medals in the latest worldwide cheese competitions in France. ${ }^{3}$

*e-mail: sibpass@yahoo.com.br
Recognition of the quality of Brazilian artisan cheese has motivated efforts to ensure its safety and quality, and one of the ways to guarantee this quality both in taste and microbiological safety is the requirement under Brazilian law of the 60-day maturation period for cheeses produced with raw milk. ${ }^{4,5}$ In order to reduce the illegal sale of cheese, state legislation approved the reduction of maturation time to 22 days for some regions of Minas Gerais State, Brazil (Araxá, Campos das Vertentes, Canastra and Cerrado), denominating half-matured cheeses (matured under 22 days) and matured cheeses (matured over 22 days). ${ }^{6}$

However, some producers do not comply with the legislation and market the cheese after a shorter maturation period (between 3 and 21 days) and name these halfmatured cheeses. This practice may endanger the health of consumers due to possible microbiological contamination, which makes the identification of cheese maturation time important for the quality evaluation of Minas artisanal cheese. . $^{3,7}$

During maturation, a series of biochemical and microbiological reactions occur, including residual lactose metabolism by lactic acid bacteria present in the 
cheese mass. Lactic acid bacteria are essential for cheese safety by synthesizing many antimicrobial compounds, including organic acids such as lactic acid, which can inhibit the growth of pathogenic bacteria, leading to cell death and lysis, contributing to the achievement of microbiological stability in the cheese and developing the typical characteristics of matured cheese to be marketed. ${ }^{8,9}$

Works published ${ }^{1,5,10,11}$ in the last few years show the characterization of the microorganisms and the effect of maturation on the microbiological features of the artisanal Minas cheese, aiming to estimate the maturation time for the cheese to be suitable for consumption.

Conventional methodologies for determining cheese maturing time use high cost and time-consuming techniques, such as electrophoresis and chromatography. There is growing interest in rapid techniques that provide accurate information on changes in cheese composition during the maturation process. ${ }^{12,13}$

Among the fast techniques, there are spectroscopic techniques such as near infrared (NIR), medium infrared (MIR) and far infrared (FIR). MIR has been most commonly used in the area of food in establishing quality parameters by identifying the functional groups assigned to food constituents, ${ }^{14}$ being applied in the identification of adulteration in raw milk, ${ }^{15}$ determination of the chemical characteristics of olive oils, ${ }^{16}$ honey quality assessment ${ }^{17}$ and coffee with different sensory characteristics. ${ }^{14}$ In cheese it can be used to determine the maturation time, authenticity and prediction of sensory attributes, making it a viable and safe alternative in determining various parameters. ${ }^{18}$ Depending on the cheese variety, different parameters are obtained as chemical characteristics of each compound, ${ }^{18}$ geographic origin monitoring, ${ }^{19}$ determination of its main components (protein, fat, lactose $)^{20}$ and changes during maturation, ${ }^{21}$ becoming a technique of rapid analysis, contributing to the reduction of the risk of cheese consumption that may cause damage to the health of the population, facilitating the inspection process. ${ }^{18,21}$

The use of multivariate techniques can be applied in monitoring the quality or authenticity parameters ${ }^{22}$ of various food products, including dairy products, from data generated from a variety of analytical methodologies such as chromatography, calorimetry, chemical and physicochemical methods and infrared spectroscopy. The analytical information present in the infrared spectrum involves the generation of a large number of complex, highly correlated variables and most of the time across the spectrum, which requires the development of classification or regression models in multivariate analysis. Regression is a technique considered useful in the construction of predictive models of changes that occur during cheese maturation. ${ }^{20,21,23}$

Considering the importance and economic value that these cheeses represent, the objective of this study was to identify the maturation time of Minas artisanal cheeses produced in the Serra do Salitre, $\mathrm{MG}$, region using analytical data and attenuated total reflection Fourier transform spectrometry (FTIR-ATR) associated with chemometric techniques.

\section{Experimental}

\section{Samples}

Samples of Minas artisanal cheeses were obtained from rural producers from Serra do Salitre, MG, Brazil. A total of 56 samples of cheese from 8 different producers were collected. The samples of artisanal cheeses were collected in August and September of 2017, the dry season of the region. The samples belonged to the same manufacturing batch of each producer and were collected on the day of manufacture (day 1) and then matured at room temperature (ca. $20-26^{\circ} \mathrm{C}$ ) in the cheese shops themselves at days 7 , $14,21,28,45$ and 60 . At the end of each maturation period the cheeses were collected, aseptically packaged, transported under refrigeration $\left(\mathrm{ca} .7^{\circ} \mathrm{C}\right.$ ) to the laboratory and fractionated in rind and crumb.

Subsequently 12 samples of Minas artisanal cheeses were purchased from the retail trade with maturation times informed on the packaging or by the seller at the time of purchase. The samples were conditioned and transported under refrigeration (ca. $7^{\circ} \mathrm{C}$ ) to the laboratory, fractionated in rind and crumb to be analyzed.

Acquisition of the spectra of the rind and crumb fractions of Minas artisanal cheese

The rind and crumb fractions of the cheese $(0.5 \mathrm{~g})$ were analyzed on an attenuated total reflection Fourier transform spectrometer (FTIR-ATR), on the equipment model Cary 630 Agilent (Technology Inc., Santa Clara, USA), equipped with attenuated total reflectance (ATR) with diamond crystal cell and deuterated triglycine sulfate detector (DTGS). The ATR diamond has a sampling surface of $1 \mathrm{~mm}$ diameter and $200 \mu \mathrm{m}$ active area and provides approximately $2 \mu \mathrm{m}$ deep of infrared energy penetration at $1700 \mathrm{~cm}^{-1}$. The spectra were obtained in the mid-infrared region, 4000 to $600 \mathrm{~cm}^{-1}$, in absorbance mode with $4 \mathrm{~cm}^{-1}$ resolution and 64 scans. The software for spectra acquisition was the Agilent MicroLab PC software. Before each collection, a background spectrum reading 
was performed and for each sample two repetitions were performed. The spectral regions and the main functional groups of the cheese analyzed in FTIR-ATR were identified according to the literature. ${ }^{12,24,25}$

\section{Analytical measurements of rind and crumb fractions}

The following analyzes were carried out on the cheese fractions: titratable acidity, percentages of moisture, ash, fat in the dry extract and total nitrogen by the Kjeldahl method. ${ }^{26}$ The $\mathrm{pH}$ was measured with a digital $\mathrm{pH}$ meter (QUIMIS model), calibrated with $\mathrm{pH} 4.0$ and 7.0 solutions. Measurements of instrumental color were performed on the $\mathrm{L}^{*}, \mathrm{a}^{*}, \mathrm{~b}^{*}$ system on a Colorquest XE colorimeter (HunterLab, Sunset Hills Reston, VA, USA), illuminant D65 and $10^{\circ}$ observer, using the CIELAB system. ${ }^{27}$ The determination of water activity $\left(a_{\mathrm{w}}\right)$ was performed on an Aqualab Series 4TE electronic water activity meter with an accuracy of \pm 0.015 and a detection range of 0.03 to $1.0 \mathrm{a}_{\mathrm{w}}$.

The percentage of nitrogen soluble in $\mathrm{pH} 4.6$ (NS $\mathrm{pH}$ 4.6) and nitrogen soluble in $12 \%$ trichloroacetic acid (TCA, Rio de Janeiro, Brazil, Vetec) (NS TCA), was determined by the Kjeldahl method only in the crumb of cheese due to proteolysis occurring more intensely in this fraction. The proteolysis extension index (PEI) was obtained by the relationship between the $\mathrm{pH} 4.6$ soluble nitrogen and total nitrogen $(\mathrm{TN})$ contents $(\mathrm{PEI}=\mathrm{NSpH} 4.6(\%) / \mathrm{TN})$, and the proteolysis depth index (PDI) was obtained by the relationship between TCA $12 \%$ soluble nitrogen and total nitrogen contents $(\mathrm{PDI}=\mathrm{NSTCA} 12 \%(\%) / \mathrm{TN})$, according to Wolfschoon and Lima. ${ }^{28}$

\section{Data processing}

The data was set in matrices $(\mathbf{m} \times \mathbf{n})$, $\mathbf{m}$ lines related to the time of maturation and $\mathbf{n}$ columns related to the variables of interest. The variables of interest used were: the absorbances associated with the different frequencies obtained from FTIR-ATR for rind (matrix A1) and crumb (matrix A2) and analytical measurements for rind (matrix A3) and crumb (matrix A4). The independent variables (analytical measurements) were standardized for mean value of 0 and standard deviation of 1 , to eliminate the differences between units of the studied variables. The spectra of the cheese were normalized using the multiplicative scatter correction (MSC) method to correct the effects of scattering of light. All multivariate analysis were performed using the software Statistical Analysis System (SAS), Student version. ${ }^{29}$
Principal component analysis (PCA)

PCA was performed from standardized data and a new coordinate system with orthogonal axes was created, originating the principal components (PC). This technique was used to identify the similarities and dissimilarities between the samples and the possible clusters from the direct observation of the score graph.

\section{Multiple linear regression (MLR)}

Initially, MLR was used to remove outlier samples of the data set obtained using FTIR-ATR and analytical measurements. Two techniques were used to remove the outliers: the Cook's distance (equation 1) and studentized residual. The samples with Cook's distance $\geq(4 / n)$, where $\mathrm{n}$ is the number of observations and with deviation of studentized residual $>3$ were considered outliers and discarded. Following, MLR was used to predict the time of maturation of the cheeses. Each group was divided in two using the Kennard-Stone algorithm, ${ }^{30}$ the first subgroup was calibration with $70 \%$ of the data (38 samples) and the second was validation with $30 \%$ of the data (18 samples). The parameters of the regression model were chosen using the Backward, Forward and Stepwise optimization methods, and the one with the lowest root mean square error of calibration (RMSEC) and root mean square error of validation (RMSEV), and higher coefficient of determination $\left(\mathrm{R}^{2}\right)$ was selected. The residual predictive deviation (RPD) and range error ratio (RER) values were used to estimate the predictive capability of the models. The RPD was calculated by dividing the standard deviation of the reference data (SD) by the RMSEV, according to equation 2, while the RER was determined dividing the reference of amplitude $\left(\mathrm{y}_{\max }-\mathrm{y}_{\min }\right)$ by RMSEV, equation $3 .{ }^{31}$

$\mathrm{D}=\frac{\sum_{\mathrm{j}=1}^{\mathrm{n}}\left(\hat{\mathrm{y}}_{\mathrm{i}}-\hat{\mathrm{y}}_{\mathrm{j}}(\mathrm{i})\right)^{2}}{\operatorname{RMSE}}$

$\mathrm{RPD}=\mathrm{SD} / \mathrm{RMSEV}$

$\operatorname{RER}=\left(\mathrm{y}_{\max }-\mathrm{y}_{\min }\right) / \mathrm{RMSEV}$

\section{Partial least squares regression (PLS)}

PLS was performed to predict the time of maturation of the analyzed cheeses. This technique can use a good number of variables as the information of the whole spectrum or its part to create a regression model. In addition to that, the method of partial least squares does not consider the 
variables as non-related. The objective of the PLS was the obtention of a regression model to predict the time of maturation using spectral data. The same criteria used in the MLR analysis were used for PLS to identify and remove outliers and to obtain the calibration and validation groups. The spectral regions used for the PLS analysis were selected by MLR analysis. The $\mathrm{R}^{2}$ and RMSE between the predicted and the actual values were calculated for the calibration and validation sets according to equations 4 and 5, respectively. The quality of the regression models was evaluated based on a high $\mathrm{R}^{2}$, RMSEV, low number of latent variables (LV). The selection of the number of latent variables in the models was carried out according to the method proposed in the software. The $\mathrm{T}^{2}$ test was used to compare whether two PRESS (predicted residual sum of squares) values were significantly different. If there was no significant difference, a more parsimonious model was chosen and only those with fewer factors were compared with the minimum PRESS model. After selecting the number of latent variables, the generated PLS model was used to predict the cheese's maturation time. RPD and RER were also estimated.

$\mathrm{R}^{2}=\sqrt{1-\left[\sum_{\mathrm{i}=1}^{\mathrm{n}}\left(\mathrm{y}_{\mathrm{i}}-\hat{\mathrm{y}}_{\mathrm{i}}\right)^{2} / \sum_{\mathrm{i}=1}^{\mathrm{n}}\left(\mathrm{y}_{\mathrm{i}}-\overline{\mathrm{y}}\right)^{2}\right]}$

$\operatorname{RMSE}=\sqrt{\sum_{\mathrm{i}=1}^{\mathrm{n}}\left(\mathrm{y}_{\mathrm{i}}-\hat{\mathrm{y}}_{\mathrm{i}}\right)^{2} / \mathrm{n}}$

where $\mathrm{n}$ is the number of samples in the test set, $\mathrm{y}_{\mathrm{i}}$ is the experimentally measured reference result for sample $\mathrm{i}, \hat{\mathrm{y}}_{\mathrm{i}}$ are the estimated results of the model for the corresponding test sample $i$, and $\bar{y}$ is the mean of all reference measurement results.

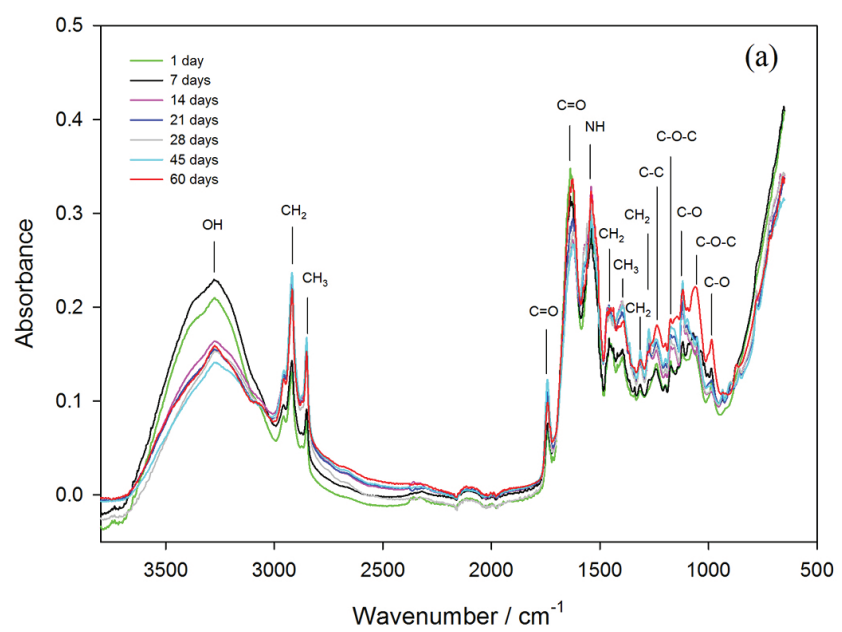

\section{Results and Discussion}

\section{Spectra characterization}

The spectra of the rind and crumb fractions were obtained by means of the sample averages at the respective maturation times $(1,7,14,21,28,45$ and 60 days) and it was possible to identify 15 peaks (maximum absorbances) that corresponded to absorption peaks attributed to the vibrations of the working groups (Figure 1).

The spectra obtained by FTIR-ATR reflect the chemical composition of the analyzed samples. Since cheese can be defined as a complex matrix consisting mainly of proteins, lipids, carbohydrates and water, modifications of these components occur over time and can be identified by FTIR, by variations in intensity and most of the peaks obtained in the spectrum (Figure 1).

It was observed in the analyzed fractions (rind and crumb) the presence of peaks in the regions between $3500-2800$ and $1700-1000 \mathrm{~cm}^{-1}$. Between 3325-3081 cm-1 it was possible to observe alteration in the peak intensity related to hydroxyl groups $(\mathrm{OH}$ stretching) elongation, while the predominant peaks located at 2918 and $2851 \mathrm{~cm}^{-1}$ were attributed to the asymmetrical and symmetrical stretching vibrations of the fatty acid groups $\left(\mathrm{CH}_{2}\right.$ and $\mathrm{CH}_{3}$ ). It was also possible to observe continuous increase of several peaks $\left(1741 \mathrm{~cm}^{-1}\right.$, stretching symmetrical $(\mathrm{C}=\mathrm{O}) ; 1400 \mathrm{~cm}^{-1}$, angular deformation $\left(\mathrm{CH}_{3}\right) ; 1314 \mathrm{~cm}^{-1}$, angular deformation $\left(\mathrm{CH}_{2}\right)$; and $1251,1173,1101$, $1078 \mathrm{~cm}^{-1}$, stretching asymmetrical/symmetrical (C-O)) of acids, esters and aliphatic chains of fatty acids and carbohydrates. ${ }^{32,33}$ According to Cevoli et al., ${ }^{18}$ most peaks identified in the middle infrared region during cheese analysis are identified and attributed to functional groups

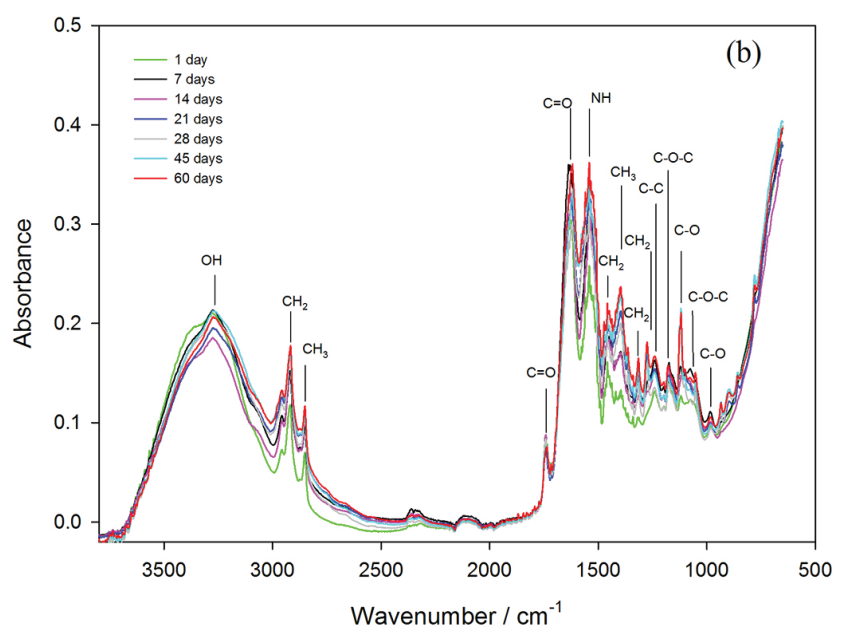

Figure 1. Cheese spectra obtained by Fourier transform infrared spectroscopy associated with total attenuated reflection (FTIR-ATR): (a) rind fraction spectrum; (b) crumb fraction spectrum. 
such as $\mathrm{CH}_{2} / \mathrm{CH}_{3}, \mathrm{C}-\mathrm{O}$ and $\mathrm{C}=\mathrm{O}$ related to triacylglycerides and ester bonds.

The peaks between 1700 and $1496 \mathrm{~cm}^{-1}$ indicate two important regions for the analyzed fractions: amide I $\left(1630 \mathrm{~cm}^{-1}\right)$ associated with symmetrical stretching of the $\mathrm{C}=\mathrm{O}$ and $\mathrm{C}-\mathrm{N}$ functional groups, and amide $\mathrm{II}\left(1541 \mathrm{~cm}^{-1}\right)$ attributed to the vibration of the $\mathrm{N}-\mathrm{H}$ angular deformation and $\mathrm{C}-\mathrm{N}$ stretching functional groups. ${ }^{34}$ Amide-related peaks describe the behavior of secondary protein structures, which, during maturation, lose polypeptide chains releasing peptides and amino acids, resulting in alterations of $\alpha$-helix, $\beta$-leaf and $\beta$-curve structures.

Amide I is more sensitive to structural changes and is most commonly used in secondary structure analysis, because it is associated with changes in casein secondary structure, protein aggregation and protein/water interaction, the $\beta$-leaf structure is more stable to these changes, which means that the amide I shows the major effects of secondary proteolysis, found in higher intensity in the rind fraction and lower in the crumb fraction. ${ }^{35,36}$ According to Karoui et al. ${ }^{37}$ amino acid side chains (glutamic acid, aspartic acid, glutamine, asparagine, lysine, arginine and tyrosine) may contribute to the intensity in the amide II region and these intensities occur with increasing cheese maturation time, which may justify the variation of the amide II signal in the spectrum.

\section{Analytical measurements}

The results of the analytical measurements of the studied cheeses presented variations in relation to the different maturation times (Tables 1 and 2). Due to the peculiar characteristics of the rind (external surface exposed to the environment) and the crumb (inner part) and the different effects that the constituents undergo in these fractions, the analyses were performed separately, showing similarities in the results found.

Table 1. Means and standard deviation of the analytical measurements of the rind fraction

\begin{tabular}{|c|c|c|c|c|c|c|c|}
\hline & \multicolumn{7}{|c|}{ Maturation time / days } \\
\hline & 1 & 7 & 14 & 21 & 28 & 45 & 60 \\
\hline Acidity / \% & $4.2 \pm 0.98$ & $6.6 \pm 3.1$ & $5.8 \pm 1.2$ & $5.5 \pm 2.3$ & $7.5 \pm 1.7$ & $9.8 \pm 2.0$ & $14.8 \pm 2.1$ \\
\hline $\mathrm{pH}$ & $6.0 \pm 0.31$ & $5.7 \pm 0.53$ & $5.6 \pm 0.47$ & $5.5 \pm 0.4$ & $5.3 \pm 0.2$ & $5.2 \pm 0.1$ & $5.1 \pm 0.2$ \\
\hline Protein / \% & $26.3 \pm 1.7$ & $25.9 \pm 1.1$ & $35.5 \pm 1.7$ & $35.2 \pm 1.6$ & $37.4 \pm 2.6$ & $39.6 \pm 2.8$ & $40.6 \pm 2.5$ \\
\hline Moisture / \% & $51.1 \pm 2.4$ & $40.0 \pm 2.0$ & $27.5 \pm 1.7$ & $21.2 \pm 1.7$ & $22.7 \pm 1.8$ & $13.7 \pm 1.4$ & $14.8 \pm 2.3$ \\
\hline Ashes / \% & $4.9 \pm 0.38$ & $5.2 \pm 1.2$ & $4.9 \pm 0.86$ & $5.9 \pm 1.1$ & $5.8 \pm 1.3$ & $5.3 \pm 1.8$ & $6.5 \pm 1.1$ \\
\hline Fat $/ \%$ & $21.0 \pm 1.5$ & $26.6 \pm 3.0$ & $31.0 \pm 2.0$ & $32.8 \pm 2.4$ & $34.0 \pm 5.5$ & $34.8 \pm 3.1$ & $34.9 \pm 2.4$ \\
\hline $\mathrm{L}^{*}$ & $84.0 \pm 7.4$ & $88.3 \pm 5.9$ & $86.4 \pm 7.7$ & $90.9 \pm 8.4$ & $88.3 \pm 9.8$ & $86.9 \pm 6.0$ & $91.0 \pm 3.3$ \\
\hline$a^{*}$ & $0.30 \pm 0.61$ & $0.96 \pm 0.54$ & $0.62 \pm 0.61$ & $0.61 \pm 0.6$ & $1.1 \pm 0.6$ & $0.98 \pm 0.7$ & $1.2 \pm 0.4$ \\
\hline$b^{*}$ & $17.1 \pm 3.5$ & $20.4 \pm 3.6$ & $17.4 \pm 4.8$ & $19.4 \pm 3.5$ & $20.4 \pm 4.6$ & $21.5 \pm 3.9$ & $21.2 \pm 5.7$ \\
\hline$\underline{\mathrm{a}_{w}}$ & $0.96 \pm 0.01$ & $0.96 \pm 0.03$ & $0.92 \pm 0.03$ & $0.88 \pm 0.03$ & $0.87 \pm 0.05$ & $0.81 \pm 0.06$ & $0.82 \pm 0.04$ \\
\hline
\end{tabular}

Acidity: expressed as a percentage of lactic acid; $L^{*}$ : brightness parameter; $\mathrm{a}^{*}$ and $\mathrm{b}^{*}$ : chromaticity coordinates; $\mathrm{a}_{\mathrm{w}}$ : water activity.

Table 2. Means and standard deviation analytical measurements of cheese crumb fraction

\begin{tabular}{|c|c|c|c|c|c|c|c|}
\hline & \multicolumn{7}{|c|}{ Maturation time / days } \\
\hline & 1 & 7 & 14 & 21 & 28 & 45 & 60 \\
\hline Acidity / \% & $5.5 \pm 1.5$ & $6.2 \pm 1.9$ & $7.1 \pm 1.6$ & $7.2 \pm 1.1$ & $8.0 \pm 2.1$ & $11.7 \pm 1.3$ & $13.8 \pm 1.4$ \\
\hline $\mathrm{pH}$ & $5.4 \pm 0.1$ & $5.7 \pm 0.2$ & $5.4 \pm 0.5$ & $5.4 \pm 0.3$ & $5.2 \pm 0.1$ & $5.1 \pm 0.1$ & $5.1 \pm 0.2$ \\
\hline Protein / \% & $21.2 \pm 2.8$ & $21.3 \pm 2.6$ & $23.4 \pm 2.8$ & $23.4 \pm 1.8$ & $26.3 \pm 1.3$ & $26.5 \pm 2.8$ & $27.6 \pm 2.5$ \\
\hline Moisture / \% & $46.4 \pm 3.5$ & $35.4 \pm 1.7$ & $34.6 \pm 1.5$ & $35.3 \pm 1.2$ & $32.6 \pm 1.4$ & $30.9 \pm 1.8$ & $28.5 \pm 3.6$ \\
\hline Ashes / \% & $3.5 \pm 0.5$ & $3.8 \pm 0.8$ & $4.2 \pm 0.8$ & $4.2 \pm 0.5$ & $4.4 \pm 0.5$ & $4.6 \pm 0.5$ & $4.7 \pm 0.5$ \\
\hline Fat $/ \%$ & $22.8 \pm 3.4$ & $30.4 \pm 4.3$ & $30.9 \pm 4.1$ & $30.9 \pm 3.7$ & $30.2 \pm 3.7$ & $33.8 \pm 4.7$ & $34.1 \pm 3.8$ \\
\hline PEI / \% & $12.3 \pm 4.9$ & $12.9 \pm 4.0$ & $13.1 \pm 2.8$ & $11.07 \pm 2.7$ & $13.2 \pm 3.4$ & $15.6 \pm 6.9$ & $28.2 \pm 5.3$ \\
\hline $\mathrm{PDI} / \%$ & $11.7 \pm 2.1$ & $12.4 \pm 1.7$ & $11.1 \pm 3.2$ & $11.8 \pm 3.9$ & $15.5 \pm 8.0$ & $15.1 \pm 7.0$ & $25.4 \pm 2.2$ \\
\hline $\mathrm{L}^{*}$ & $86.3 \pm 7.4$ & $86.4 \pm 5.9$ & $91.3 \pm 7.7$ & $90.9 \pm 8.4$ & $88.3 \pm 9.8$ & $86.9 \pm 6.0$ & $90.8 \pm 3.3$ \\
\hline$a^{*}$ & $1.1 \pm 0.3$ & $0.62 \pm 0.5$ & $0.71 \pm 0.6$ & $0.61 \pm 0.6$ & $1.1 \pm 0.6$ & $0.98 \pm 0.7$ & $1.2 \pm 0.4$ \\
\hline $\mathrm{b}^{*}$ & $19.1 \pm 3.7$ & $17.4 \pm 3.6$ & $19.3 \pm 4.8$ & $19.4 \pm 3.5$ & $20.4 \pm 4.6$ & $21.5 \pm 3.9$ & $21.9 \pm 5.7$ \\
\hline$\underline{\mathrm{a}_{\mathrm{w}}}$ & $0.97 \pm 0.01$ & $0.95 \pm 0.02$ & $0.93 \pm 0.01$ & $0.92 \pm 0.01$ & $0.94 \pm 0.01$ & $0.90 \pm 0.02$ & $0.89 \pm 0.02$ \\
\hline
\end{tabular}

Acidity: expressed as a percentage of lactic acid; PEI: proteolysis extension index; PDI: proteolysis depth index; L*: brightness parameter; $a^{*}$ and $b^{*}$ : chromaticity coordinates; $\mathrm{a}_{\mathrm{w}}$ : water activity. 
Over time there was a tendency of increasing acidity and reducing $\mathrm{pH}$, moisture and $\mathrm{a}_{\mathrm{w}}$ parameters of the fractions (rind and crumb). Humidity reduction and $\mathrm{a}_{\mathrm{w}}$ may be justified by water loss during maturation, leading to the concentration of solids, mainly of fats and proteins with increasing maturation time. This increase can be noticed in the spectral regions (2900-2860 and $1400-1101 \mathrm{~cm}^{-1}$ ) associated with the functional groups of fatty acids and esters and the region 1700-1469 $\mathrm{cm}^{-1}$ to amide I and amide II, these peaks with more intensity were expected due to the fat and protein found in the analytical measurements.

During proteolysis, the formation of ionic groups occurs, which causes the $\mathrm{pH}$ reduction of the cheese and increase of the acidity, also related to the conversion of lactose to lactic acid by the action of bacteria present in the yeast, using residual lactose. The increase in the parameters of length and depth indexes in the crumb fraction indicates protein hydrolysis and proteolysis in cheese.

\section{Principal component analysis}

Spatial separation of FTIR-ATR samples was defined by two principal components $\mathrm{PC} 1$ and $\mathrm{PC} 2$, which described for the rind fraction $76.09 \%$ for $\mathrm{PC} 1$ and $19.10 \%$ for $\mathrm{PC} 2$ of the total variance. For the crumb fraction, $\mathrm{PC} 1$ represented $65.80 \%$ while PC2 explained $23.55 \%$, totaling $89.35 \%$ of the total data variance (Figure 2).

The PC1 was the component that best represented the data distribution of the matrices A1 and A2 (rind and crumble, respectively), which means it was the responsible for the separation of the samples for the two fractions analyzed. For the rind, PC1 correlated positively $(p<0.05)$ with the wavenumbers present in the regions between 2900-2800, 1400-1290, 1280-1160 and $986 \mathrm{~cm}^{-1}$, characteristic peaks associated with fats and esters, these regions being of major importance and determining the changes that occurred in the cheese over the maturation times. The PC 2 correlated with the $1741 \mathrm{~cm}^{-1}$ wavenumber associated with the esters. For the cheese crumb fraction the PC1 correlated positively with the wavenumbers in the regions 2900-2800, 1590-1430, 1400-1290, 1280-1160 and $986 \mathrm{~cm}^{-1}$, associated with esters functional groups, and PC2 correlated with 1636 and $1101 \mathrm{~cm}^{-1}$, being associated with protein and fat esters, respectively, which are the most important and necessary to separate the cheese according to the maturing time (half-matured and matured).

Samples classified as half-matured (32 samples) were separated from those labeled as matured (24 samples) based on functional groups associated with fats $\left(\mathrm{CH}_{3}\right.$ and $\mathrm{C}-\mathrm{C}$ symmetrical stretching $)$ and proteins $(\mathrm{C}=\mathrm{O}$ stretching and $\mathrm{N}-\mathrm{H}$ angular deformation) correlated with $\mathrm{PC} 1$ for rind and crumb. During the maturation process, the concentration of the dried extract increases as a result of the reduction of the moisture content of the cheese, which will increase the absorbance of the functional groups representing proteins and lipids.

The application of PCA to the analytical data (matrix A3) set of each cheese fraction provided important information describing the changes in cheese composition over time (Tables 1 and 2).

For the cheese rind (Figure 3a), PC1 explained a percentage of $54.56 \%$ of the data variance, this PC is a contrast between water and non-aqueous components correlating negatively $(p \leq 0.05)$ with humidity and $\mathrm{a}_{\mathrm{w}}$, and positively with protein and fat. Contrary behavior was observed for the crumb fraction (matrix A4) (Figure 3b), where the 2 PCs together explained $80.73 \%$ of the data
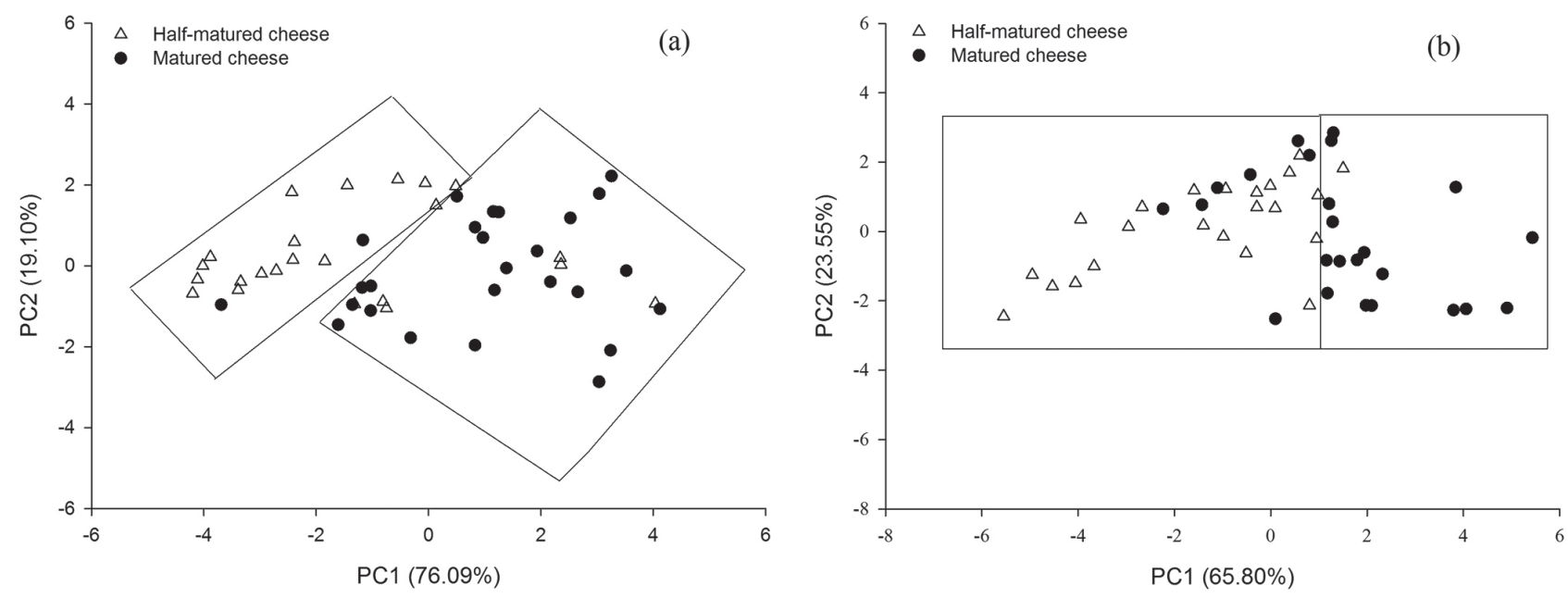

Figure 2. Score plot of Minas artisanal cheese samples for (a) rind and (b) crumb for FTIR-ATR data. 

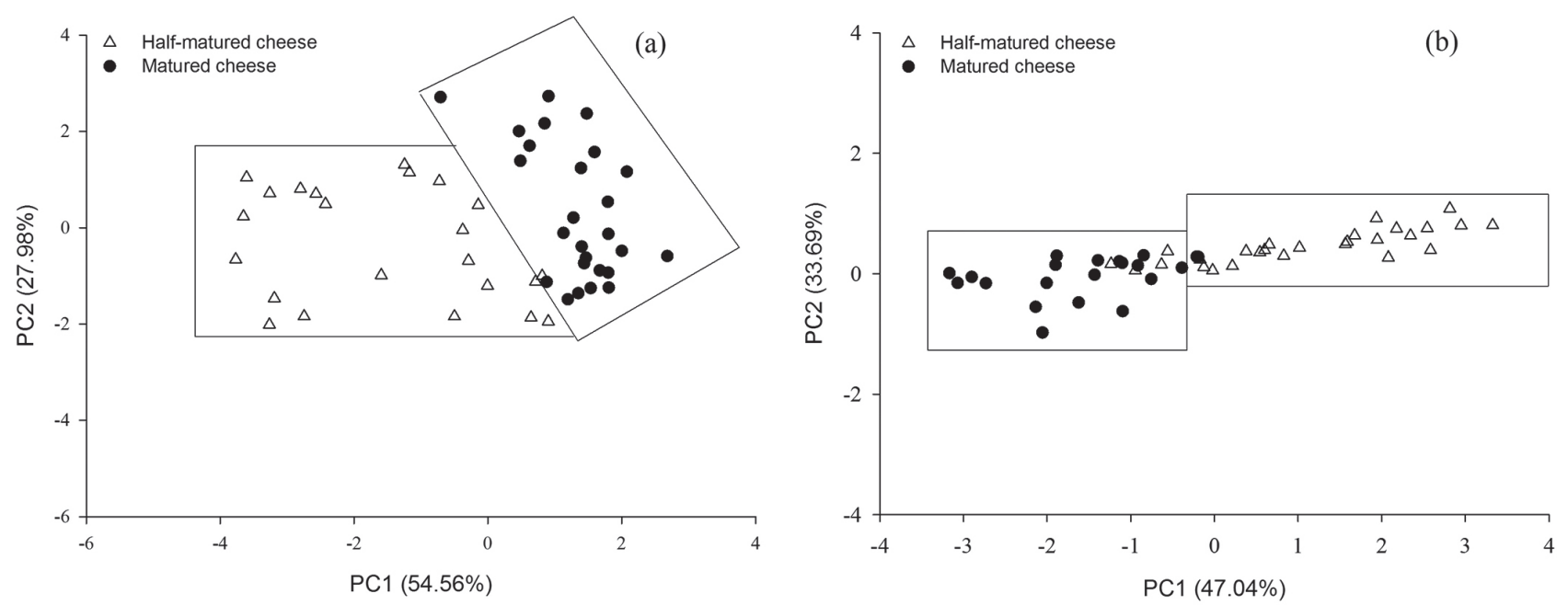

Figure 3. Score plot of Minas artisanal cheese samples for (a) rind and (b) crumb for the analytical measurements data.

variance, $\mathrm{PC} 1$ being responsible for the separation of the samples according to the maturation time.

The reduction in moisture and $\mathrm{a}_{\mathrm{w}}$ during the cheese maturation process occurs because the hydrolysis of peptide bonds leads to the formation of polar ionic groups $\left(\mathrm{COO}^{-}\right.$and $\left.\mathrm{NH}_{3}^{+}\right)$that bind to 'free water' through altering hydrogen bonds, altering the state of the water in the cheese, in addition, water loss may occur in the ripening environment.

During the maturation time, the moisture and $a_{w}$ parameters decreased, and the protein and fat constituents concentration increased, allowing to conclude that these parameters were sufficient to separate the samples into half-matured and matured cheeses. In the cheese rind these effects were more intense, probably due to the greater exposure of this fraction to the ambient conditions.

\section{Multiple linear regression}

The MRL was applied to the spectra obtained with the purpose of removing the outliers and identifying the spectra regions that contributed to the prediction of the maturation time. The Forward method had the highest coefficient of determination $\left(\mathrm{R}^{2}=0.87\right)$ and lowest RMSEC (8.57 days) among the tested methods for matrix A1, FTIR-ATR rind fraction, resulting in a model with 12 parameters for rind fraction (Figure 4a). The value of validation of $\mathrm{R}^{2}$ can be explained by the greater variability of cheese rind by being exposed to maturation conditions such as light, ambient temperature and realistic humidity. The validation generated $\mathrm{R}^{2}$ of 0.76 , RMSEV of 9.81 days, correlation of $0.87, \mathrm{RPD}=2.04$ and $\mathrm{RER}=6.01$. According to Chang et al. , $^{38}$ the accuracy of the model is satisfactory when the RPD is higher than 2. Therefore, the model can be considered fair to predict the maturation time. Models with RER lower than 3 present little practical utility, models with RER between 3 and 10 have limited practical utility and models with RER higher than 10 have high practical utility, ${ }^{39}$ which indicates that the model generated by MLR for the FTIR-ATR data of the rind presents little practical utility. These results can be explained by the rapid balance with the environment that the rind achieves in the first days of maturation by significantly reducing its humidity, therefore increasing the solid content, which difficult the occurrence of perceptible changes during long periods of maturation, such as proteolysis and lipolysis.

According to the MRL for the rind fraction, the wavenumbers $2918 \mathrm{~cm}^{-1}$ corresponding to the vibrations of the functional group $\left(\mathrm{CH}_{2}\right.$ asymmetrical stretching), $2851 \mathrm{~cm}^{-1}$ associated with $\mathrm{CH}_{3}$ symmetrical stretching, $1449\left(\mathrm{CH}_{3}\right.$ angular deformation), 1314 and $1078 \mathrm{~cm}^{-1}(\mathrm{C}-\mathrm{O}$ symmetrical stretching $)$ attributed to lipids, $1741 \mathrm{~cm}^{-1}(\mathrm{C}=\mathrm{O}$ stretching) and $1251 \mathrm{~cm}^{-1}(\mathrm{C}-\mathrm{O}$ asymmetrical stretching) of the esters and $1541 \mathrm{~cm}^{-1}(\mathrm{~N}-\mathrm{H}$ angular deformation) of amide II were the parameters that most contributed to the identification of maturation time (Figure 4a). This behavior can be explained because during cheese maturation the proteins and triglycerides are hydrolyzed by milk proteases and lipases, respectively, resulting in the release of peptides and free fatty acids.

For the FTIR-ATR spectra of the crumb fraction, matrix A2 data, the Forward method was the best fit for the MLR model. For the cheese fraction in the calibration step, 11 parameters were part of the model (Figure 4b), with $\mathrm{R}^{2}$ of 0.92 , RMSEC of 6.7 days, correlation of 0.959 . The validation of the data presented $R^{2}=0.82$, RMSEV of 8.1 days, correlation of 0.90 , RPD of 2.4 and RER of 7.27. The results for the crumble fraction using FTIR-ATR 

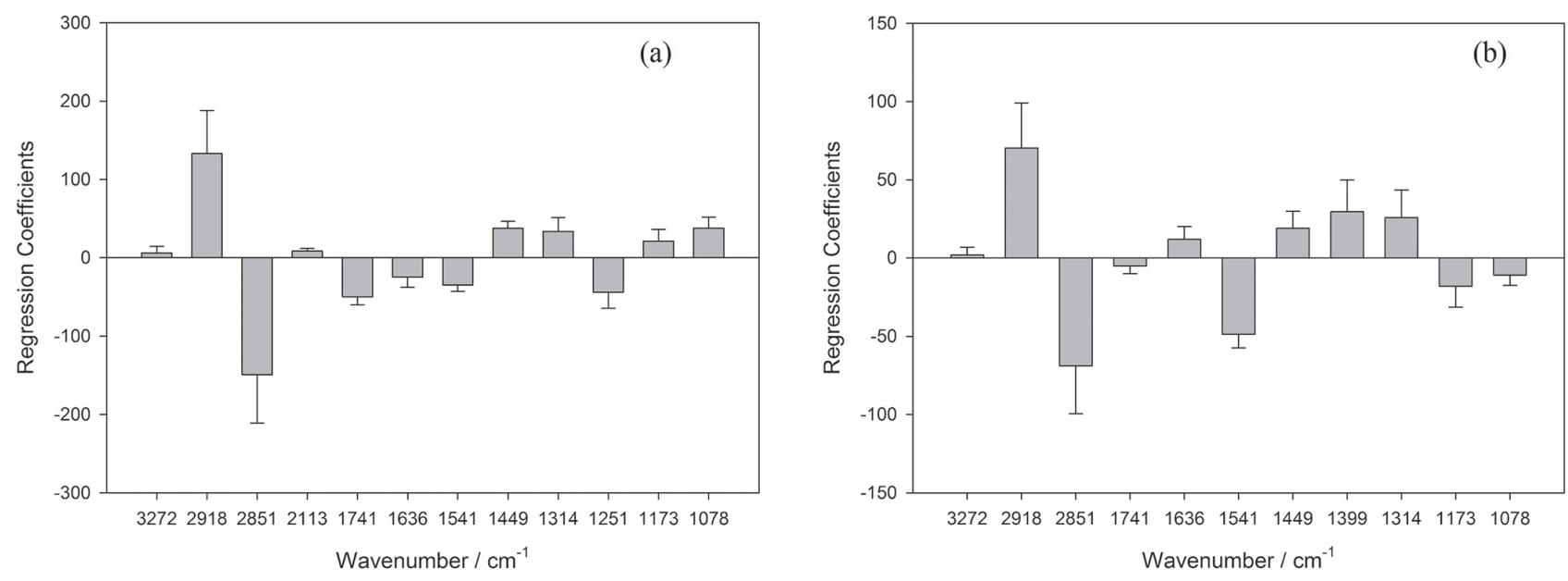

Figure 4. Regression coefficients with the respective wavenumbers that make up the regression model for (a) rind and (b) crumb for FTIR-ATR data.

presented models with little practical utility to predict the studied maturation times.

The crumb fraction spectra showed intensity variations at peaks: 2918 (asymmetrical stretching $\left(\mathrm{CH}_{2}\right)$ ), 2851 (symmetrical stretching $\left.\left(\mathrm{CH}_{3}\right)\right), 1449$ and 1399 (angular deformation, "scissors" $\left(\mathrm{CH}_{3}\right)$ ), and $1314 \mathrm{~cm}^{-1}$ (angular deformation, "scissors" $\left(\mathrm{CH}_{2}\right)$ ) which are groups associated with aliphatic chains in the fatty acid and $1541 \mathrm{~cm}^{-1}$, associated with the vibrations angular deformation $(\mathrm{N}-\mathrm{H})$ attributed to amide II, and these peaks contributed mostly to the formation of the regression model to predict the maturation times (Figure $4 \mathrm{~b}$ ).

When MLR was applied to the analytical measure data for the fractions of crumb and rind, matrices $\mathbf{A 3}$ and A4, respectively, the Forward method was the best fit. The application of the MLR to the data obtained from the analytical measurements allowed to obtain a mathematical function able to identify the cheese maturation time. For the rind fraction in the calibration step, a determination coefficient of 0.94, an RMSEC of 5.5 days and a correlation of 0.97 were obtained, which indicate a good accuracy of the cheese maturation time prediction model. Of the 9 variables that make up the regression model, humidity and acidity were the variables that most contributed to the prediction of maturation times. Although the data of the analytical measurements suggested that the humidity was an important factor in the determination of the time of maturation in the MLR analysis, the absorbances related to the vibration of water in the FTIR-ATR, regions of 3766,3657 and $1595 \mathrm{~cm}^{-1}$, were not considered determinant to the estimation of the time of maturation.

Figure 5a displays the correlations between the predicted and real maturation times, the $\mathrm{R}^{2}$, RMSEV, RPD and RER of the validation step, the results displayed indicate the model is limited to predict the maturation time,
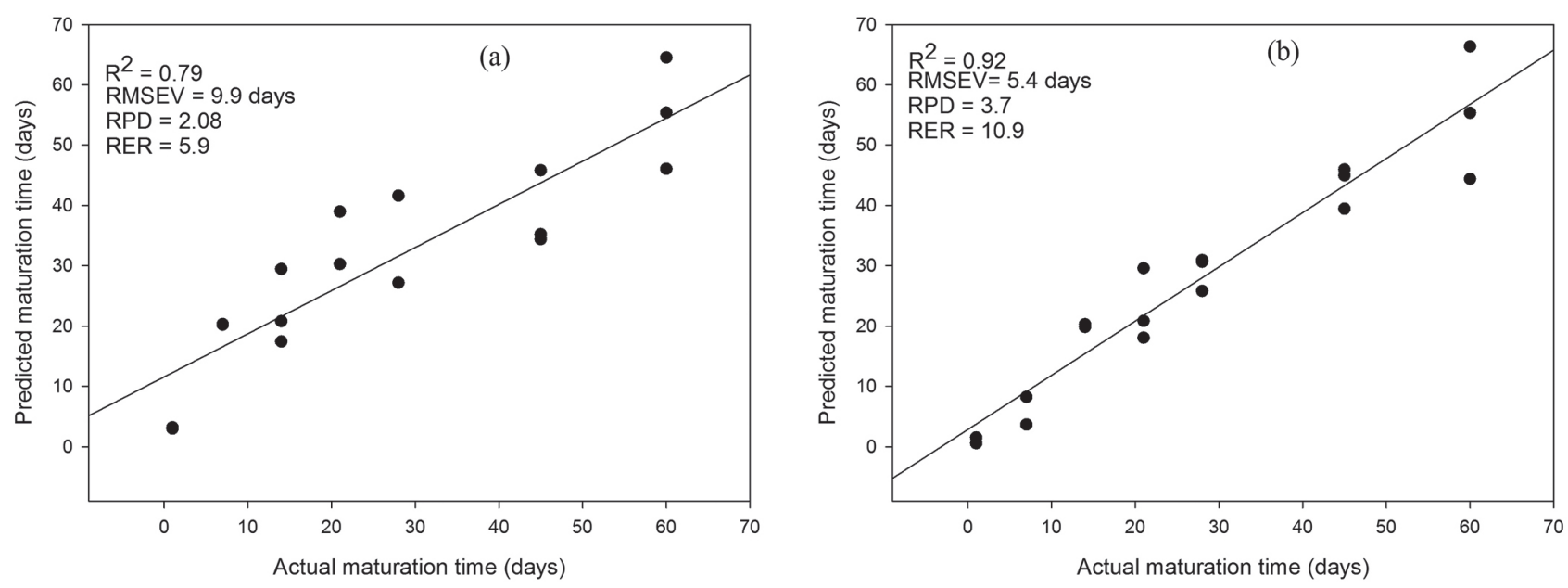

Figure 5. Regression models showing the correlation of predicted times with actual maturation times of (a) rind and (b) crumb for analytical measurements data. 
similar result to the MLR of the FTIR-ATR data for the rind fraction, concluding that this method is not suitable to predict the maturation time of the cheeses using the rind fraction.

The crumb fraction resulted in a good predictive model, requiring 7 parameters to predict or identify the maturation time. The MLR technique was adequate for the objective proposed in this work, presenting a high $\mathrm{R}^{2}$ value of 0.93 , RMSEC of 5.55 days and correlation of 0.96 in data calibration. Figure 5b displays the results of the validation step. The results indicate that the crumb fraction is more adequate to predict the maturation time.

\section{Partial least squares regression}

Two PLS models were obtained, one for the rind fraction and one for the crumb. Considering the sensitivity of the FTIR-ATR analytical technique, good results were obtained for the analyzed fractions. The determination coefficients for data calibration were 0.81 and 0.90 for rind and crumb, respectively, indicating good accuracy of the prediction models. It took 5 and 4 latent variables for rind and crumb, respectively, to explain the data variation. The smaller number of significant latent variables makes the model more robust to predict values with a low associated error (RMSE), in which for the rind the RMSEC was 8.6 days and for the crumb 6.6 days. The results for the crumb fraction were confirmed by the good correlation between the predicted and observed values (Figure 6b). The most important variables in the prediction of maturation times were the peaks present in the regions of amide I: $1697-1677 \mathrm{~cm}^{-1}$ (stretching $(\mathrm{C}=\mathrm{O})$ ), 1358-1310 $\mathrm{cm}^{-1}$ (angular deformation "scissors" $\left(\mathrm{CH}_{2}\right)$ ) and 1237-1177 $\mathrm{cm}^{-1}$ (symmetrical stretching $(\mathrm{C}-\mathrm{O}))$, corresponding to esters and lipids of

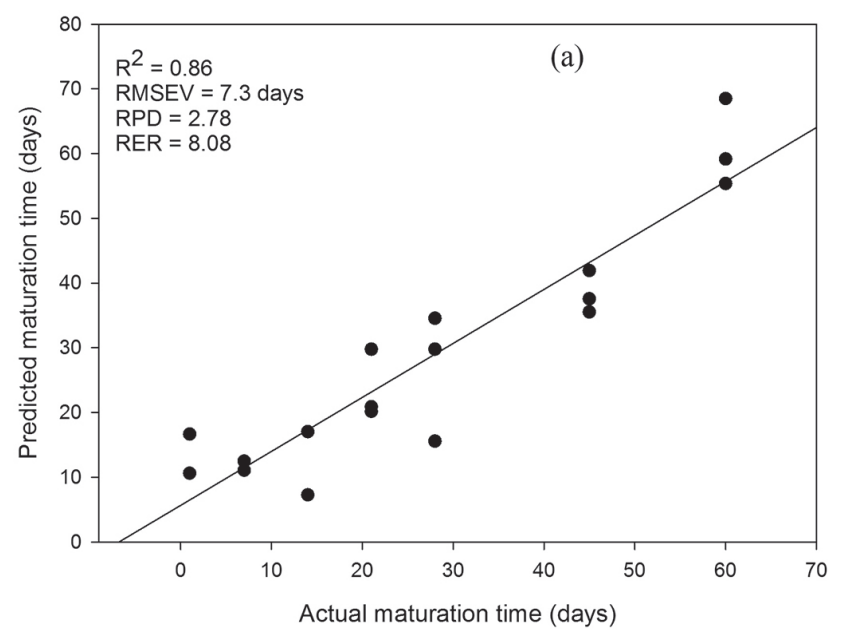

the shell fraction. For the crumb, 1628-1564 $\mathrm{cm}^{-1}$ regions associated with amide I and amide II, and 1374-1311 $\mathrm{cm}^{-1}$ (angular deformation scissors $\left(\mathrm{CH}_{2}\right)$ ) and 1184-1135 $\mathrm{cm}^{-1}$ (symmetrical stretching $(\mathrm{C}-\mathrm{O})$ ) regions associated with esters and lipids, confirmed that protein and lipid variables change during cheese maturation and may differentiate them according to the maturation time.

Scatter plots (Figure 6) illustrate the correlation between actual maturation times and those predicted by the model of the analyzed fractions. Overall, FTIR-ATR performance can be considered superior in determining maturation times by obtaining fast data and without sample preparation, because the results of this technique were similar to the results obtained by the analytical measurements for the crumb fraction. Thus, this technique can be pointed as the most suitable for the investigation of the maturation time of the studied cheeses.

\section{Commercial samples}

Commercial samples were screened by applying PCA applied to FTIR-ATR data and analytical measurements to see if they behaved like half-matured or matured cheeses (Figure 7).

In a first observation it was possible to identify that the majority of the samples behaved like half-matured cheeses for the data obtained for the two fractions.

From these observations, it was possible to identify the maturation times of these samples, testing the general capacity of the models validated for FTIR-ATR data. Based on figures of merit, RMSEV, $\mathrm{R}^{2}$, RER and RPD, PLS was the most adequate method to verify the validation of the commercial samples for the crumb fraction using FTIR-ATR data. Among the commercial samples of cheese analyzed, $58 \%$ presented different time of maturation of the

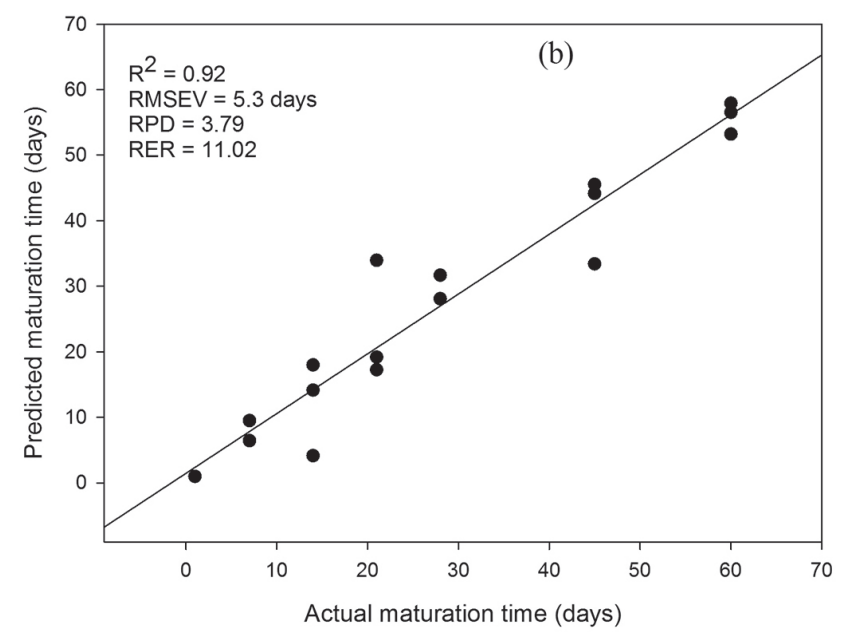

Figure 6. Predicted and actual values of cheese maturation time for validation data for PLS regression of (a) rind and (b) crumb for FTIR-ATR data. 

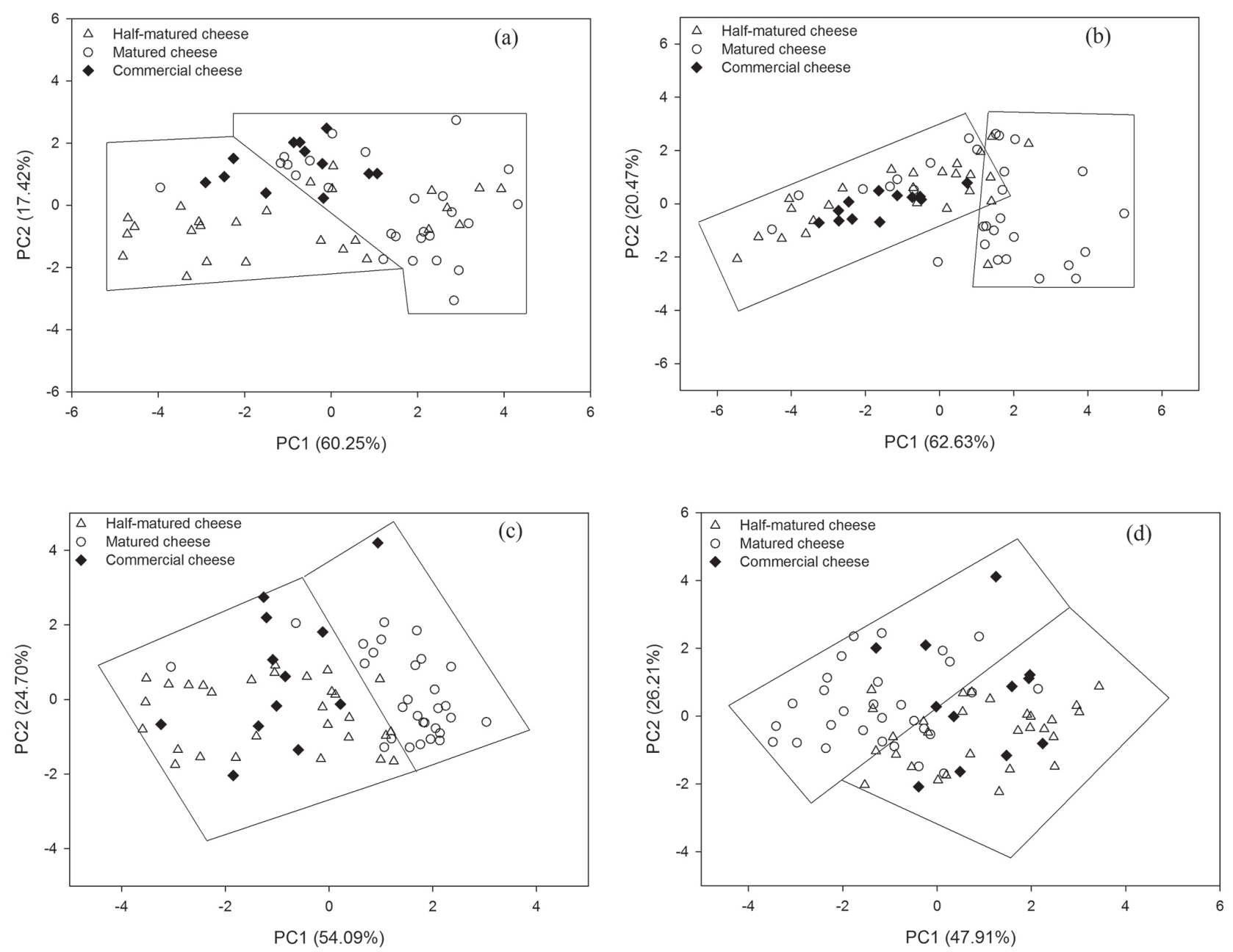

Figure 7. Score plot of Minas artisanal cheese samples and commercial samples for (a) rind and (b) crumb, using FTIR-ATR and (c) rind and (d) crumb data from analytical measurements.

time displayed on the package and $42 \%$ had declared values below the RMSEV (5.3 days). The commercialization of these cheeses obtained from raw milk with maturation times lower than the necessary for the reactions to inactivate the pathogenic microorganisms can risk the consumer's health. The methodology developed in this work presents great potential of application, for it can estimate rapidly the time of maturation of the cheeses, it can serve as a triage analysis to allow the inspection of a larger number of products. In the cases of inconsistencies between the values declared and estimated by this method, conventional techniques can be applied to confirm the results, improving the security to the consumer. However, it is important to consider the limitations of the calibration methods (few samples, relatively high prevision error, etc.), for that reason the authors inform that the methods developed in this work will be kept active and updated to assure its efficiency for future needs of analysis as new samples of cheese become available.

\section{Conclusions}

The study indicates viability and efficiency of the use of FTIR-ATR associated with chemometrics in the prediction of the maturation of Minas artisanal cheeses. The predictive model obtained by PLS was able to predict the time of maturation of commercial samples using the crumb fraction of the cheeses, indicating that this technique can be used as a rapid triage analysis to predict the time of maturation of the cheeses for large numbers of samples to verify.

This study confirms the technical adequation of the FTIR-ATR technique to predict the maturation of the cheeses. Although it does not eliminate the necessity of more detailed chemical analysis, it can help on the selection of samples that present discrepancies between the labeled and model time. Furthermore, the developed models will be kept active and updated to ensure the reliability of these results. 


\section{Acknowledgments}

The authors thank Coordination for the Improvement of Higher Education Personnel (CAPES) for providing scholarships and the Federal University of Minas Gerais (UFMG) and the Minas Gerais Institute of Agriculture (Belo Horizonte, Brazil) for helping with sample collection.

\section{Author Contributions}

Josane C. de Jesus was responsible for the formal analysis, data curation, investigation, methodology, project administration and writing original draft; Grazielly J. Silva and Ben-Hur R. F. Gonçalves for the data curation and investigation; Marcelo R. de Souza for the resources; Leandro S. Santos for the conceptualization, formal analysis and supervision; Sibelli P. B. Ferrão for the conceptualization, supervision, project administration and writing review and editing.

\section{References}

1. Cardoso, V. M.; Borelli, B. M.; Lara, C. A.; Soares, M. A.; Pataro, C.; Bodevan, E. C.; Rosa, C. A.; Food Res. Int. 2015, 69, 331.

2. Fialho, T. L.; Carrijo, L. C.; Magalhães, J. M. J.; Baracat, P. M. C.; Piccoli, R. H.; Abreu, L. R.; Food Res. Int. 2018, 107, 406.

3. Bemfeito, R. M.; Rodrigues, J. F.; e Silva, J. G.; Abreu, L. R.; J. Dairy Sci. 2016, 99, 7886.

4. Ministério da Agricultura, Pecuária e Abastecimento (MAPA); Resolução No. 07, de 28 de novembro de 2000; Anexo I: Critérios de Funcionamento e de Controle da Produção de Queijarias, para Seu Relacionamento Junto ao Serviço de Inspeção Federal; Departamento de Inspeção de Produtos de Origem Animal, Brasília, 2000. Available at http://www. engetecno.com.br/port/legislacao/leite_func_contr_queijarias. htm, accessed in May 2020.

5. Campagnollo, F. B.; Margalho, L. P.; Kamimura, B. A.; Feliciano, M. D.; Freire, L.; Lopes, L. S.; Alvarenga, V. O.; Cadavez, V. A. P.; Gonzales, B. U.; Schaffner, D. W.; Sant'ana, A. S.; Food Microbiol. 2018, 73, 288.

6. Instituto Mineiro de Agropecuária (IMA); Portaria No. 1305, de 30 de abril de 2013; Estabelece Diretrizes para a Produção do Queijo Minas Artesanal; IMA, Belo Horizonte, Brazil, 2013. Available at http://www.ima.mg.gov.br/ index.php?preview $=1 \&$ option $=$ com_dropfiles $\&$ format $=$ $\&$ task=frontfile. download $\&$ catid $=1575 \& \mathrm{id}=15649 \&$ Item $\mathrm{id}=1000000000000$, accessed in May 2020.

7. Castro, R. D.; Oliveira, L. G.; Sant'Anna, F. M.; Luiz, L. M. P.; Sandes, S. H. C.; Silva, C. I. F.; Silva, A. M.; Nunes, A.
C.; Penna, C. F. A. M.; Souza, M. R.; J. Dairy Sci. 2016, 99 , 6086.

8. Souza, V.; Melo, P. C.; Medeiros, M. I. M.; Conde, S. O.; Nader, F. A.; Ars Vet. 2015, 31, 19.

9. Cruz, A. G.; Zacaechenco, P. B.; Oliveira, C. A. F.; Corassin, C. H.; Processamento de Produtos Lácteos: Queijos, Leites Fermentados, Bebidas Lácteas, Sorvete, Manteiga, Creme de Leite, Doce de Leite, Soro em Pó e Lácteos Funcionais, $1^{\text {st }}$ ed.; Elsevier: Rio de Janeiro, Brazil, 2017.

10. Sant'Anna, F. M.; Wetzels, S. U.; Cicco, S. H. S.; Figueiredo, R. C.; Sales, G. A.; Figueiredo, N. C.; Nunes, C. A.; Esser, S. S.; Mann, E.; Wagner, M.; Souza, M. R.; Food Microbiol. 2019, 82, 349.

11. Martins, J. M.; Galinari, É.; Pimentel-Filho, N. J.; Ribeiro Jr., J. I.; Furtado, M. M.; Ferreira, C. L. L. F.; Braz. J. Microbiol. 2015, 46, 219.

12. Lerma, G. M. J.; Ramis, R. G.; Herrero, M. J. M.; Simó, A. E. F.; Food Chem. 2010, 118, 78.

13. Gan, H. H.; Yan, B.; Linforth, R. S. T.; Fisk, I. D.; Food Chem. 2016, 190, 442.

14. Belchior, V.; Botelho, B. G.; Oliveira, L. S.; Franca, A. S.; Food Chem. 2019, 273, 178.

15. Conceição, D. G.; Gonçalves, B.-H. R. F.; da Hora, F. F.; Faleiro, A. S.; Santos, L. S.; Ferrão, S. P. B.; J. Braz. Chem. Soc. 2019 , 30,780 .

16. Uncu, O.; Tokatli, B. O. F.; Talanta 2019, $201,65$.

17. Svečnjak, L.; Jović, O.; Prđun, S.; Rogina, J.; Marijanović, Z.; Car, J.; Matošević, M.; Jerković, I.; Food Chem. 2019, 291, 187.

18. Cevoli, C.; Gori, A.; Nocetti, M.; Cuibus, L.; Caboni, M. F.; Fabbri, A.; Food Res. Int. 2013, 52, 220.

19. Karoui, R.; Mazerolles, G.; Bosset, J. O.; Baerdemaeker, J.; Food Chem. 2007, 105, 847.

20. Marchi, M. D.; Penasa, M.; Zidi, A.; Manuelian, C. L.; J. Dairy Sci. 2018, 101, 10589.

21. Loudiyi, M.; Aït-Kaddour, A.; Food Res. Int. 2018, 105, 221.

22. Botelho, B. G.; Mendes, B. A. P.; Sena, M. M.; Food Anal. Methods 2013, 6, 881.

23. Gori, A.; Maggio, R. M.; Cerretani, L.; Nocetti, M.; Caboni, M. F.; Int. Dairy J. 2012, 23, 115.

24. Karoui, R.; Dufour, E.; Pillonel, L.; Schaller, E.; Picque, D.; Cattenoz, T.; Bosset, J.-O.; Int. Dairy J. 2005, 15, 287.

25. Rodriguez, S. L. E.; Koca, N.; Harper, W. J.; Alvarez, V. B.; J. Dairy Sci. 2006, 89, 1407.

26. Latimer, G. W.; Official Methods of Analysis of AOAC International, $18^{\text {th }}$ ed; AOAC International: Washington, 2016.

27. Commission Internationale de L'Éclairage (CIE); Colorimetry, $2^{\text {nd }}$ ed.; CIE Publication: Vienna, 1996.

28. Wolfschoon, P. A. F.; Lima, A.; Rev. Inst. Laticinios Candido Tostes 1989, 44, 54.

29. Statistical Analysis System (SAS), Student version; SAS Institute Inc., USA, 2018.

30. Kennard, R. W.; Stone, L. A.; Technometrics 1969, 11, 137. 
31. Lima, A. B. S.; Batista, A. S.; Jesus, J. C.; Silva, J. J.; Araújo, A. C. M.; Santos, L. S.; Food Control 2020, 107, 106.

32. Koca, N.; Rodriguez, S. L. E.; Harper, W. J.; Alvarez, V. B.; J. Dairy Sci. 2007, 90, 3596.

33. Pavia, D. L.; Lampman, G. M.; Kriz, G. S.; Vyvyan, J. R.; Introdução à Espectroscopia, $4^{\text {th }}$ ed.; Cengage Learning: São Paulo, Brazil, 2010.

34. Kulmyrzaev, A.; Dufour, E.; Noel, Y.; Hanafi, M.; Karoui, R.; Qannari, E. M.; Mazerolles, G.; Int. Dairy J. 2005, 15, 669.

35. Fennema, O. R.; Parkin, K. L.; Damodaran, S.; Química de Alimentos de Fennema, $4^{\text {th }}$ ed.; Artmed: Porto Alegre, Brazil, 2010.
36. Glassford, S. E.; Byrne B.; Kazarian, S. G.; Biochim. Biophys. Acta, Proteins Proteomics 2013, 1834, 2849.

37. Karoui, R.; Mazerolles, G.; Dufour, E.; Int. Dairy J. 2003, 13, 607.

38. Chang, C. W.; Laird, D. A.; Mausbach, M. J.; Hurburgh Jr., C. R.; Soil Sci. Soc. Am. J. 2001, 65, 480.

39. Williams, P. C.; Sobering, D. C.; J. Near Infrared Spectrosc. 1993, $1,25$.

Submitted: November 1, 2019

Published online: May 26, 2020 